\title{
Ventilator Liberation for High-Risk-for-Failure Patients: Improving Value of the Spontaneous Breathing Trial
}

\author{
Niranjan Jeganathan MD, Carl A Kaplan MD, and Robert A Balk MD \\ Introduction \\ Cardiopulmonary Interactions and Physiology During SBT and \\ Postextubation \\ SBT Using a T-Piece Is Better Than Minimal Pressure Support for HRFF \\ Patients \\ In HRFF Patients, Weaning Predictors Should Be Assessed Without \\ Pressure Support During the SBT \\ Longer Weaning Trials May Be Considered for HRFF Patients \\ Other Methods to Assess HRFF Patients \\ Arterial Blood Gas Measured at the End of an SBT in HRFF Patients Aids \\ in Identifying Those Who Would Benefit From Noninvasive Ventilation \\ Conclusions
}

\begin{abstract}
Several patient populations have been identified as high risk for extubation failure despite successful completion of a spontaneous breathing trial (SBT). Extubation failure and subsequent need for emergent re-intubation have been associated with increased morbidity and mortality. In this review, we discuss ways to optimize the value and performance of the SBT in a subgroup of high-risk patients (elderly, cardiac, and/or respiratory failure) to reduce the rate of extubation failure. We recommend the use of T-piece mode, longer duration SBT, and measurement of the rapid shallow breathing index (breathing frequency/tidal volume in $L$ ) off ventilatory support to increase the predictive value of the SBT. In addition, measurement of changes in central venous oxygen saturation and serum brain natriuretic peptide, and measurements of mitral inflow and annular velocity using bedside transthoracic echocardiography with tissue Doppler imaging may help guide the clinician in determining who and when to extubate and thus minimize the rate of extubation failure. Arterial blood gas analysis performed at the end of the SBT may help determine who will benefit from prophylactic use of noninvasive ventilatory support postextubation. Key words: weaning; acute respiratory failure; artificial ventilation; ventilatory support; spontaneous breathing trial; extubation; re-intubation; high risk for failure. [Respir Care 2015;60(2):290-296. (C) 2015 Daedalus Enterprises]
\end{abstract}

\section{Introduction}

Liberating critically ill patients from mechanical ventilation typically involves a daily assessment of their respi- ratory status, improvement in the clinical issues that necessitated ventilatory support, decreased sedation, and performance of a spontaneous breathing trial (SBT). Use of a weaning protocol that incorporates a daily SBT became common in clinical practice following a randomized

\footnotetext{
The authors have disclosed no conflicts of interest.
}

The authors are affiliated with the Division of Pulmonary and Critical Care Medicine, Rush University Medical Center and Rush Medical College, Chicago, Illinois. 
controlled trial that showed a shorter duration of mechanical ventilation (4.5 vs $6 \mathrm{~d}$ ) and fewer complications compared to clinician-guided weaning. ${ }^{1}$ Although the majority of patients with acute respiratory failure who pass an SBT will easily wean from ventilatory support, postextubation respiratory failure may develop in $\sim 10-25 \%$ of patients. ${ }^{2-10}$

Extubation failure, irrespective of the baseline severity of the underlying illness, has been shown to be associated with higher morbidity and mortality. ${ }^{2,3}$ The mortality rate in re-intubated patients is as high as $43 \%$ compared to only $12 \%$ in those successfully extubated. ${ }^{3}$ Complications associated with the re-intubation process such as cardiac arrest, arrhythmias, and aspiration pneumonia may occur in up to $28 \%$ of patients. ${ }^{2}$ Patients who require re-intubation also have an increased risk of developing pneumonia and sepsis. ${ }^{7,10,11}$ Frutos-Vivar et al ${ }^{7}$ reported that $31 \%$ of re-intubated subjects developed ventilator-associated pneumonia, and $21 \%$ developed sepsis. Re-intubated patients have longer ICU and hospital stays and increased transfer rates to long-term acute care facilities. ${ }^{3}$

Several risk factors for extubation failure have been identified in prior studies. These risk factors include impaired neurological status, poor cough, increased secretions, peak expiratory flow $\leq 60 \mathrm{~L} / \mathrm{min}$, hemoglobin $\leq 100 \mathrm{~g} / \mathrm{L}$, rapid shallow breathing index (RSBI; breathing frequency/tidal volume in L) of $>105$, high Acute Physiology and Chronic Health Evaluation II score at time of weaning, and a positive fluid balance state. . $^{3,8,12-16} \mathrm{~Pa}-$ tients who are elderly 3,10 or patients with chronic respiratory ${ }^{10,12,17}$ and/or cardiac ${ }^{3,10}$ diseases have generally been identified in a number of studies as a high-risk-for-failure (HRFF) population who are at increased risk for extubation failure and therefore are at increased risk for morbidity and mortality. In patients $>65$ y of age with chronic respiratory and/or cardiac disease, the re-intubation rate is $34 \%$ compared to $9 \%$ in younger patients without these risk factors. ${ }^{10}$ Patients who fail weaning due to respiratory failure and congestive heart failure have a higher mortality rate than those who fail due to airway-related causes, such as upper airway obstruction, aspiration, or increased secretions (53\% vs 17\%). ${ }^{2}$ In this review, our focus is on how to optimize the value and performance of SBTs in HRFF patients to improve the predictive value of the test and therefore reduce extubation failure rate. Clinical trials focusing specifically on the HRFF population are very limited; therefore, the recommendations provided are our

\footnotetext{
Correspondence: Niranjan Jeganathan MD, Division of Pulmonary and Critical Care Medicine, Rush University Medical Center, 297 Jelke South Center, 1750 W Harrison St, Chicago, IL 60612. E-mail: niranjan_ jeganathan@rush.edu.
}

DOI: $10.4187 /$ respcare.03111 own based on the available evidence. Although not discussed here, there may be other populations considered to be HRFF for whom our recommendations may be applicable, such as patients with neuromuscular weakness or prolonged mechanical ventilator dependence. ${ }^{18-20}$

\section{Cardiopulmonary Interactions and Physiology During SBT and Postextubation}

There are many changes in the cardiopulmonary physiology that occur during the transition from positive-pressure supported to negative-pressure unsupported spontaneous breathing. The success of weaning depends on the ability of the respiratory system and cardiac pump to tolerate these changes. Postextubation, patients may experience an increase in ventilatory load on respiratory muscles due to bronchospasm, glottic edema, increased airway secretions, and/or sputum retention. ${ }^{2,21}$ Patients with COPD can develop intrinsic PEEP and dynamic hyperinflation. ${ }^{22}$ Intrinsic PEEP can decrease venous return to the right heart, increase right ventricular afterload, and increase pulmonary vascular resistance, which can result in right ventricular failure. ${ }^{23}$ Dynamic hyperinflation increases the work of breathing by affecting the efficiency of diaphragmatic and respiratory muscle function. Transfer from positive-pressure ventilation to spontaneous ventilation is associated with increased cardiac venous return (preload) and increased left ventricular afterload from the negative intrathoracic pressure generation. ${ }^{24}$ In patients with coronary artery disease, this could induce myocardial ischemia, ${ }^{25}$ and in those with cardiac compromise, this could result in decreased forward flow and impaired perfusion and precipitate cardiac failure or cardiogenic shock. ${ }^{26}$

Once their acute illness has resolved, most patients are able to tolerate any increase in airway resistance and hemodynamic changes associated with spontaneous breathing. ${ }^{4}$ However, patients with COPD and congestive heart failure may not sustain their breathing in the face of this increased work load if they are extubated prematurely. Tobin ${ }^{27}$ stated, "If there is any reason to fear that a patient might experience respiratory difficulties following extubation, it is incumbent on a physician to try to replicate the conditions that the patient will face after extubation but do so before removal of the endotracheal tube." The SBT is the time to identify the patients who are not ready to be extubated. In one study, subjects failing an SBT were noted to have increased gastric mucosal ischemia (decreased gastric intramucosal $\mathrm{pH}$, a marker of splanchnic hypoperfusion) and a decline in central venous oxygen (a marker of decreased oxygen delivery or increased consumption) levels compared to those with successful weaning. ${ }^{28,29}$ A marked increase in the pulmonary artery occlusion pressure and left ventricular diastolic volume index was observed in patients with severe COPD and cardiovascular 
disease who failed weaning trials. After appropriate diuresis, patients were successfully weaned without a change in pulmonary artery occlusion pressure. ${ }^{26}$ Therefore, with an optimal SBT and close monitoring of respiratory and cardiac indices, one will likely be able to identify signs of cardiopulmonary failure in patients who are not ready to be extubated. It is particularly helpful in the HRFF patient population to replicate the mode and duration of SBT as close to the conditions the patient will face postextubation.

\section{SBT Using a T-Piece Is Better Than Minimal Pressure Support for HRFF Patients}

An SBT can be performed with patients breathing through the endotracheal or tracheostomy tube without any ventilatory support (ie, through a T-piece) or with minimal ventilatory support (ie, low-level pressure support, automatic tube compensation, and/or CPAP). It has become common practice to perform an SBT with minimal pressure support because it requires less monitoring since the patient remains connected to the ventilator with the associated alarms and back-up ventilation if needed. In addition, in a randomized controlled clinical trial comparing SBT using a T-piece versus pressure support ventilation (PSV), a higher percentage of subjects in the PSV group passed the SBT (22\% vs $14 \%$ ), and there was no difference in the re-intubation rate. ${ }^{4}$ Similarly, studies comparing T-piece to automatic tube compensation ${ }^{30}$ and T-piece to $\mathrm{CPAP}^{31}$ showed no difference in re-intubation rates. However, these clinical studies were limited due to the small number of subjects, and the study designs were not powered to detect a difference in the HRFF population.

The rational for performing an SBT with minimal ventilatory support is to overcome the increased airway resistance imposed by the endotracheal tube, which may contribute to weaning failure. However, this assumption fails to account for the common occurrence of upper airway edema or laryngeal lesions, ${ }^{32}$ which could impose additional work load on patients after extubation. Experimental studies have shown that the work of breathing measured at the end of a 2-h T-piece trial is equivalent to postextubation respiratory load. ${ }^{21}$ Use of any level of pressure support decreases the inspiratory load significantly. In a small study of subjects with acute respiratory failure of various etiologies, the use of CPAP $\left(5 \mathrm{~cm} \mathrm{H}_{2} \mathrm{O}\right)$ and PSV ( $5 \mathrm{~cm} \mathrm{H}_{2} \mathrm{O}$ ) decreased the work of breathing by $40 \%$ and $36 \%$, respectively, compared to a T-piece. ${ }^{33}$ In a study of difficult-to-wean subjects who failed a T-piece SBT trial, $57 \%$ and $79 \%$ passed when placed on PSV $\left(7 \mathrm{~cm} \mathrm{H}_{2} \mathrm{O}\right)$ or PSV + PEEP (7 and $5 \mathrm{~cm} \mathrm{H}_{2} \mathrm{O}$ ), respectively. ${ }^{34}$ Left ventricular heart failure was observed in $70 \%$ of these subjects during a T-piece trial, but only in 50\% using PSV and $30 \%$ using PSV + PEEP. ${ }^{34}$ These studies demonstrate the potential for minimal ventilatory support during an SBT to enhance the patient's ability to successfully complete the trial. The physiological evidence shows that use of any mode other than T-piece does not simulate postextubation conditions. Use of any support in HRFF patients during the SBT may mask a significant risk for cardiopulmonary compromise, leading to extubation failure once the endotracheal tube is removed and the patient is liberated from ventilatory support. However, we recognize that there are no clinical studies to support this argument. It is possible that use of a T-piece may, in some patients, lead to increased false negatives (failing the SBT when they are truly ready to extubate) and therefore unnecessarily prolong mechanical ventilation. However, in conjunction with a T-piece, we believe that with appropriate patient selection (HRFF patients), proper clinical judgment, and utilization of additional diagnostic tools, we will be able to decrease the rate of extubation failure without increasing the risk of prolonged mechanical ventilation.

\section{In HRFF Patients, Weaning Predictors Should Be Assessed Without Pressure Support During the SBT}

Weaning predictors (objective physiologic measurements) used to assess readiness to liberate from a ventilator may also be affected by the mode of ventilation. Yang and Tobin ${ }^{35}$ analyzed multiple variables to assess their usefulness in predicting weaning outcomes. They concluded that an RSBI of $<105$ measured with a handheld spirometer attached to a breathing tube before an SBT was the most accurate predictor of weaning outcome. The RSBI measured in this manner had a sensitivity of $97 \%$ in predicting weaning success defined as both successful SBT and not requiring re-intubation within $24 \mathrm{~h}$. The falsepositive rate was $36 \% .{ }^{35}$ In routine practice, the RSBI is measured before the SBT (to determine who would benefit from an SBT) and during the SBT (to determine who can be successfully extubated). The use of PSV or PEEP during the SBT could lower the patient's RSBI significantly and influence the physician's decision in favor of extubation. In a study comparing varying approaches to an SBT in a difficult-to-wean population (failed the first SBT attempt), the median RSBI was 92 during a T-piece trial compared to 89 during a PSV trial and 58 during a PSV + PEEP SBT. ${ }^{34}$ In a general group of ventilated subjects considered ready to undergo an extubation trial by their ICU team, $100 \%$ had an RSBI of $<105$ during a PSV and CPAP SBT. However, 36\% had an RSBI of $>105$ when placed on a T-piece for the SBT. ${ }^{36}$ Another study with a significant number of HRFF subjects (congestive heart failure was present in 56.2\% and COPD in $52.5 \%$ of subjects) compared CPAP to a T-piece. Using 5 and $0 \mathrm{~cm} \mathrm{H}_{2} \mathrm{O} \mathrm{CPAP}, 35 \%$ and $26 \%$ of the RSBI, respectively, were erroneously deemed adequate for extubation compared to a T-piece. ${ }^{37}$ The lower RSBI seen with 
$0 \mathrm{~cm} \mathrm{H}_{2} \mathrm{O}$ CPAP was attributed to the base flow delivered by several modern ventilators, which provides a small amount of pressure support. ${ }^{37}$ Recently, there has been an increased interest in assessing breath-to-breath breathing pattern variability as another predictor of successful weaning. Patients with decreased breathing pattern variability have been shown to have a higher incidence of extubation failure. ${ }^{38,39}$ Use of any type of pressure support has been shown to reduce the predictive performance of breathing pattern variability compared to T-piece weaning in a general group of ICU patients. ${ }^{40}$ Therefore, the use of a threshold RSBI of 105 or assessing breathing pattern variability during an SBT using PSV or CPAP mode may provide a false assurance that the patient is ready to be liberated from ventilatory support and could result in premature discontinuation. However, the evidence is limited, as the studies did not evaluate extubation outcomes and were not focused specifically on the HRFF population. Regardless, the implications would be expected to be more pronounced in this population. These notions need to be confirmed in clinical studies focusing on HRFF patients.

\section{Longer Weaning Trials May Be Considered for HRFF Patients}

Earlier studies performed SBT for durations of at least 2 h. ${ }^{41,42}$ However, 2 randomized studies comparing SBT for a duration of 30-120 min in all ventilated subjects ready to be weaned showed no difference in the rate of re-intubation between the groups. ${ }^{5,43}$ These findings have resulted in the use of shorter duration SBT in clinical practice. It is noteworthy that these studies had a small number of HRFF subjects. Therefore, the validity of these findings in an HRFF population is unknown, and the results should be extrapolated with caution in this population. In the study by Esteban et al, ${ }^{5}$ although there was no statistically significant difference in the number of subjects failing the SBT, the median time to fail was less in the 30-min SBT group compared to the 120-min SBT group (15 vs $30 \mathrm{~min}$, respectively). One explanation for this discrepancy could be a difference in the baseline risk factors in favor of the 30-min SBT group. In an observational study of ventilated subjects who failed an SBT, $40 \%$ of those with COPD failed between 30 and 120 min. ${ }^{14}$ In an elderly population ( $\geq 70 \mathrm{y}$ of age) in which $67 \%$ had cardiac disease and 36\% had COPD, an 8-h SBT followed by a 2-h SBT the next day compared to a 2-h SBT alone significantly decreased the re-intubation rate $(7.5 \%$ vs $48 \%) .{ }^{44}$ Even though data supporting a longer SBT are limited, it may be prudent to err on the side of caution and recommend a 2-h SBT in the HRFF population.

\section{Other Methods to Assess HRFF Patients}

Successful weaning from mechanical ventilation depends not only on adequate respiratory strength and endurance, but also on optimal cardiac performance. ${ }^{45}$ The weaning parameters commonly used in clinical practice assess only the respiratory load during an SBT and do not assess the imposed load on the heart. Studies have shown that measurements of central venous oxygen and serum brain natriuretic peptide (BNP) during an SBT could be useful tools to predict extubation failure due to cardiovascular dysfunction. ${ }^{46-48}$ In a group of difficult-to-wean patients (failed the first weaning attempt), a decline in central venous oxygen by $4.5 \%$ between baseline and a $30-\min$ SBT predicted extubation failure with a sensitivity of $88 \%$, specificity of $95 \%$, positive predictive value of $93 \%$, and negative predictive value of $90 \% .{ }^{48}$ In a prospective observational study (55\% of subjects had COPD), an aminoterminal pro-BNP level of $<1,000 \mathrm{pg} / \mathrm{mL}$ ruled out postextubation respiratory distress with $95 \%$ sensitivity and a negative likelihood ratio of 0.09 .47 In a study of subjects with acute respiratory failure from pneumonia or COPD, a change in BNP level of $<20 \%$ between baseline and a 2-h SBT predicted extubation success with a sensitivity of $91 \%$ and positive predictive value of $97 \%$. Incorporating this threshold value of BNP into the routine SBT in a subsequent validation study increased the extubation success rate from $78 \%$ to $95 \% .45$ Even though the above studies did not focus entirely on the HRFF population, these tools could be valuable in this population, which is more likely to have left (systolic and diastolic dysfunction) and right heart dysfunction.

Point-of-care ultrasonography is now commonly used in many ICUs. There has been increased interest in using bedside transthoracic echocardiography to identify subclinical heart failure during weaning trials. ${ }^{49-52}$ Studies have shown that assessment of early diastolic mitral inflow (E), late diastolic mitral inflow (A), and early diastolic mitral annular velocity $\left(\mathrm{E}^{\prime}\right)$ using tissue Doppler imaging and the resulting $\mathrm{E} / \mathrm{A}$ and $\mathrm{E} / \mathrm{E}^{\prime}$ ratios correlate with the left ventricular filling pressure. ${ }^{50-52} \mathrm{In}$ a group of subjects who had previously failed SBTs, a combination of E/A $>0.95$ and $\mathrm{E} / \mathrm{E}^{\prime}>8.5$ at the end of an SBT trial predicted weaninginduced elevation in pulmonary artery occlusion pressure $(\geq 18 \mathrm{~mm} \mathrm{Hg}$ ) with $82 \%$ sensitivity and $91 \%$ specificity..$^{50} \mathrm{In}$ a small study of mechanically ventilated subjects, an E/E' cutoff value of 14.5 during an SBT trial had a sensitivity of $75 \%$ and specificity of $95.8 \%$ in predicting failure of extubation (4/20 subjects) or failure of SBT (16/20 subjects). ${ }^{53}$ Further studies with focus on HRFF patients could establish ultrasound as a very useful tool during the SBT assessment. 


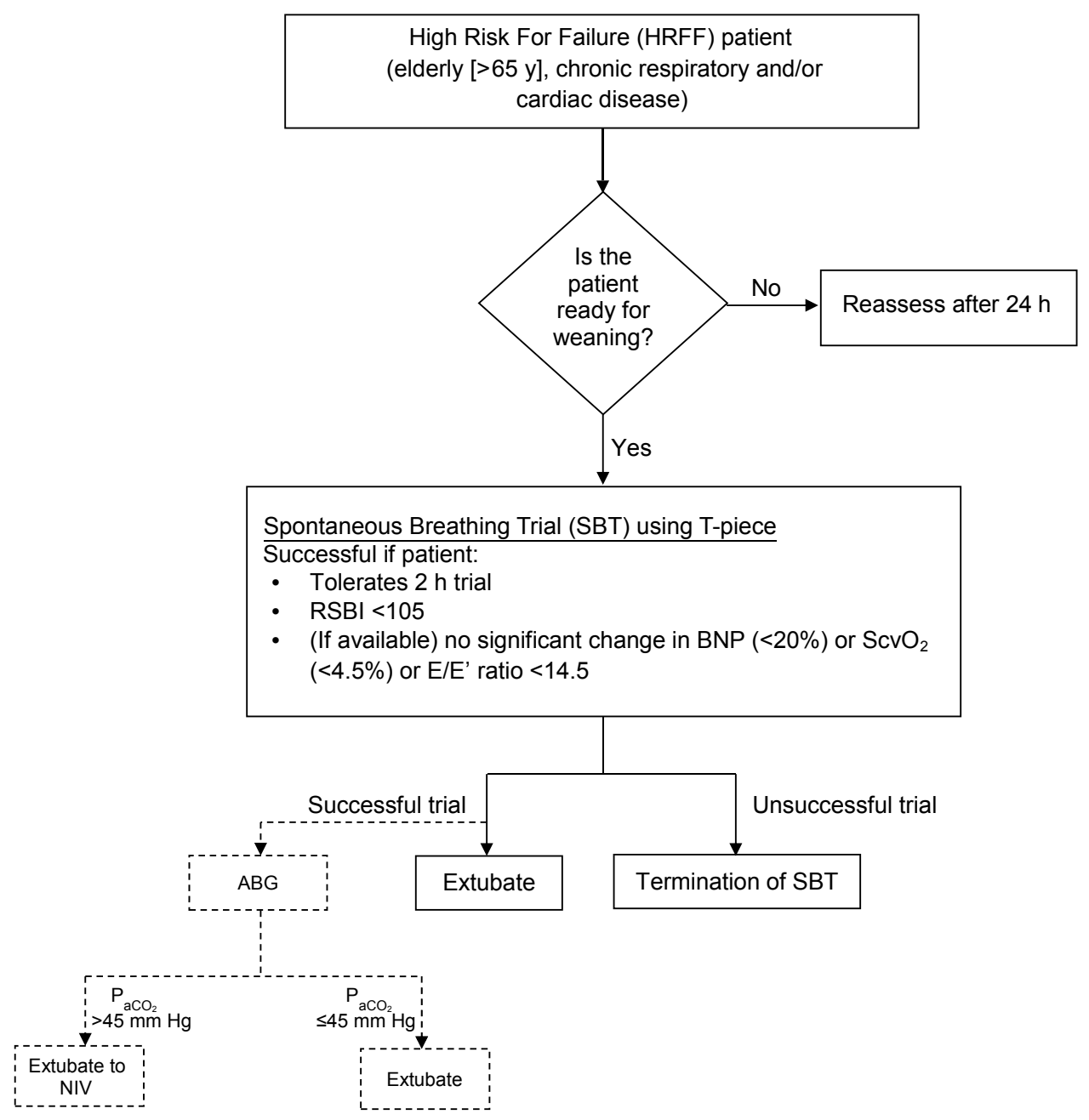

Fig. 1. Weaning strategy for the high-risk-for-failure (HRFF) population. Solid lines = main algorithm; dashed lines = optional algorithm. $\mathrm{RSBI}=$ rapid shallow breathing index; $\mathrm{BNP}=$ serum brain natriuretic peptide; $\mathrm{ABG}=$ arterial blood gas; NIV = noninvasive ventilation; $\mathrm{E} / \mathrm{E}^{\prime}=$ early diastolic mitral inflow/early diastolic mitral annular velocity.

\section{Arterial Blood Gas Measured at the End of an SBT in HRFF Patients Aids in Identifying Those Who Would Benefit From Noninvasive Ventilation}

In subjects with chronic respiratory disorders who tolerated an SBT but had a $\mathrm{P}_{\mathrm{aCO}_{2}}$ of $>45 \mathrm{~mm} \mathrm{Hg}$ at the end of an SBT trial, use of prophylactic noninvasive ventilation (NIV) compared to standard therapy decreased postextubation respiratory failure (15\% vs $48 \%$ ) and 90 -d mortality $(11 \%$ vs $31 \%) .{ }^{54}$ Similarly, another study with a significant number of HRFF subjects $(80 \%$ of $>65 \mathrm{y}$ of age, $33 \%$ with heart failure, and $51 \%$ with chronic respiratory disorders) showed decreased postextubation respiratory failure and ICU mortality with prophylactic NIV (in the subgroup analysis, the difference was statistically significant only in subjects with hypercapnia during the SBT). ${ }^{55}$ These studies did not show a difference in reintubation rates between the prophylactic NIV and stan- dard therapy groups (most subjects were treated with rescue NIV) due to the small number of re-intubated subjects in both groups. Further studies are needed to evaluate the benefit of NIV in HRFF patients. However, based on the available evidence, it may be prudent to perform an arterial blood gas analysis at the end of the SBT in those HRFF patients with advanced cardiac or pulmonary disease. In those who are found to be hypercapnic, use of prophylactic NIV postextubation could facilitate the weaning process by decreasing the risk of re-intubation and ventilator-associated complications.

\section{Conclusions}

Weaning HRFF patients from mechanical ventilatory support is a complex clinical problem. Patients who are elderly or who have chronic respiratory disease and/or heart failure are at increased risk for extubation failure and 
may benefit from management with a weaning algorithm specifically tailored to minimize the risk for postextubation respiratory failure and need for re-intubation (Fig. 1). Extubation failure has been shown to be associated with an increase in mortality related to re-intubation and the complications that develop after re-intubation. If extubated prematurely, these patients may have difficulty tolerating the increased work of breathing secondary to laryngeal edema, dynamic hyperinflation of lungs, and cardiac overload (systolic and diastolic dysfunction). An SBT in these patients should be performed using a T-piece, which is the best method to replicate the conditions they will experience postextubation. Weaning trials should be performed for a longer duration (120 min) in HRFF patients. Measurement of the RSBI in these patients should be performed off ventilatory support using a spirometer to produce more reliable measurements. Central venous oxygen and BNP measurements and bedside transthoracic echocardiography with tissue Doppler imaging could be useful adjunctive tools to assess subclinical heart failure during an SBT. In a select population, performing an arterial blood gas analysis at the end of the SBT may help identify those who could benefit from prophylactic application of NIV immediately postextubation.

\section{REFERENCES}

1. Ely EW, Baker AM, Dunagan DP, Burke HL, Smith AC, Kelly PT, et al. Effect on the duration of mechanical ventilation of identifying patients capable of breathing spontaneously. N Engl J Med 1996; 335(25):1864-1869.

2. Epstein SK, Ciubotaru RL. Independent effects of etiology of failure and time to reintubation on outcome for patients failing extubation. Am J Respir Crit Care Med 1998;158(2):489-493.

3. Epstein SK, Ciubotaru RL, Wong JB. Effect of failed extubation on the outcome of mechanical ventilation. Chest 1997;112(1):186-192.

4. Esteban A, Alía I, Gordo F, Fernández R, Solsona JF, Vallverdú I, et al. Extubation outcome after spontaneous breathing trials with Ttube or pressure support ventilation. The Spanish Lung Failure Collaborative Group. Am J Respir Crit Care Med 1997;156(2 Pt 1):459465.

5. Esteban A, Alía I, Tobin MJ, Gil A, Gordo F, Vallverdú I, et al. Effect of spontaneous breathing trial duration on outcome of attempts to discontinue mechanical ventilation. Spanish Lung Failure Collaborative Group. Am J Respir Crit Care Med 1999;159(2):512518.

6. Esteban A, Ferguson ND, Meade MO, Frutos-Vivar F, Apezteguía $\mathrm{C}$, Brochard L, et al. Evolution of mechanical ventilation in response to clinical research. Am J Respir Crit Care Med 2008;177(2):170177.

7. Frutos-Vivar F, Esteban A, Apezteguía C, González M, Arabi Y, Restrepo MI, et al. Outcome of reintubated patients after scheduled extubation. J Crit Care 2011;26(5):502-509.

8. Frutos-Vivar F, Ferguson ND, Esteban A, Epstein SK, Arabi Y, Apezteguía $\mathrm{C}$, et al. Risk factors for extubation failure in patients following a successful spontaneous breathing trial. Chest 2006;130(6): 1664-1671.

9. Nava S, Gregoretti C, Fanfulla F, Squadrone E, Grassi M, Carlucci A, et al. Noninvasive ventilation to prevent respiratory failure after extubation in high-risk patients. Crit Care Med 2005;33(11):24652470.

10. Thille AW, Harrois A, Schortgen F, Brun-Buisson C, Brochard L. Outcomes of extubation failure in medical intensive care unit patients. Crit Care Med 2011;39(12):2612-2618.

11. Torres A, Gatell JM, Aznar E, el-Ebiary M, Puig de la Bellacasa J, González J, et al. Re-intubation increases the risk of nosocomial pneumonia in patients needing mechanical ventilation. Am J Respir Crit Care Med 1995;152(1):137-141.

12. Mokhlesi B, Tulaimat A, Gluckman TJ, Wang Y, Evans AT, Corbridge TC. Predicting extubation failure after successful completion of a spontaneous breathing trial. Respir Care 2007;52(12):1710-1717.

13. Smina M, Salam A, Khamiees M, Gada P, Amoateng-Adjepong Y, Manthous CA. Cough peak flows and extubation outcomes. Chest 2003;124(1):262-268.

14. Vallverdú I, Calaf N, Subirana M, Net A, Benito S, Mancebo J. Clinical characteristics, respiratory functional parameters, and outcome of a two-hour T-piece trial in patients weaning from mechanical ventilation. Am J Respir Crit Care Med 1998;158(6):1855-1862.

15. Namen AM, Ely EW, Tatter SB, Case LD, Lucia MA, Smith A, et al. Predictors of successful extubation in neurosurgical patients. Am J Respir Crit Care Med 2001;163(3 Pt 1):658-664.

16. Khamiees M, Raju P, DeGirolamo A, Amoateng-Adjepong Y, Manthous CA. Predictors of extubation outcome in patients who have successfully completed a spontaneous breathing trial. Chest 2001; 120(4):1262-1270.

17. Robriquet L, Georges H, Leroy O, Devos P, D'Escrivan T, Guery B. Predictors of extubation failure in patients with chronic obstructive pulmonary disease. J Crit Care 2006;21(2):185-190.

18. Vianello A, Arcaro G, Braccioni F, Gallan F, Marchi MR, Chizio S, et al. Prevention of extubation failure in high-risk patients with neuromuscular disease. J Crit Care 2011;26(5):517-524.

19. Huang CT, Yu CJ. Conventional weaning parameters do not predict extubation outcome in intubated subjects requiring prolonged mechanical ventilation. Respir Care 2013;58(8):1307-1314.

20. Thille AW, Richard JC, Brochard L. The decision to extubate in the intensive care unit. Am J Respir Crit Care Med 2013;187(12):12941302.

21. Straus C, Louis B, Isabey D, Lemaire F, Harf A, Brochard L. Contribution of the endotracheal tube and the upper airway to breathing workload. Am J Respir Crit Care Med 1998;157(1):23-30.

22. Boles JM, Bion J, Connors A, Herridge M, Marsh B, Melot C, et al. Weaning from mechanical ventilation. Eur Respir J 2007;29(5): 10331056.

23. Jubran A, Tobin MJ. Pathophysiologic basis of acute respiratory distress in patients who fail a trial of weaning from mechanical ventilation. Am J Respir Crit Care Med 1997;155(3):906-915.

24. Pinsky MR. Breathing as exercise: the cardiovascular response to weaning from mechanical ventilation. Intensive Care Med 2000; 26(9):1164-1166.

25. Chatila W, Ani S, Guaglianone D, Jacob B, Amoateng-Adjepong Y, Manthous CA. Cardiac ischemia during weaning from mechanical ventilation. Chest 1996;109(6):1577-1583.

26. Lemaire F, Teboul JL, Cinotti L, Giotto G, Abrouk F, Steg G, et al. Acute left ventricular dysfunction during unsuccessful weaning from mechanical ventilation. Anesthesiology 1988;69(2):171-179.

27. Tobin MJ. Extubation and the myth of "minimal ventilator settings." Am J Respir Crit Care Med 2012;185(4):349-350.

28. Mohsenifar Z, Hay A, Hay J, Lewis MI, Koerner SK. Gastric intramural $\mathrm{pH}$ as a predictor of success or failure in weaning patients from mechanical ventilation. Ann Intern Med 1993;119(8):794-798.

29. Jubran A, Mathru M, Dries D, Tobin MJ. Continuous recordings of mixed venous oxygen saturation during weaning from mechanical 


\section{Ventilator Liberation for High-Risk Patients}

ventilation and the ramifications thereof. Am J Respir Crit Care Med 1998;158(6):1763-1769.

30. Haberthür C, Mols G, Elsasser S, Bingisser R, Stocker R, Guttmann J. Extubation after breathing trials with automatic tube compensation, T-tube, or pressure support ventilation. Acta Anaesthesiol Scand 2002;46(8):973-979.

31. Jones DP, Byrne P, Morgan C, Fraser I, Hyland R. Positive endexpiratory pressure vs T-piece. Extubation after mechanical ventilation. Chest 1991;100(6):1655-1659.

32. Tadié JM, Behm E, Lecuyer L, Benhmamed R, Hans S, Brasnu D, et al. Post-intubation laryngeal injuries and extubation failure: a fiberoptic endoscopic study. Intensive Care Med 2010;36(6):991-998.

33. Sassoon CS, Light RW, Lodia R, Sieck GC, Mahutte CK. Pressuretime product during continuous positive airway pressure, pressure support ventilation, and T-piece during weaning from mechanical ventilation. Am Rev Respir Dis 1991;143(3):469-475.

34. Cabello B, Thille AW, Roche-Campo F, Brochard L, Gómez FJ, Mancebo J. Physiological comparison of three spontaneous breathing trials in difficult-to-wean patients. Intensive Care Med 2010; 36(7):1171-1179.

35. Yang KL, Tobin MJ. A prospective study of indexes predicting the outcome of trials of weaning from mechanical ventilation. N Engl J Med 1991;324(21):1445-1450.

36. El-Khatib MF, Zeineldine SM, Jamaleddine GW. Effect of pressure support ventilation and positive end expiratory pressure on the rapid shallow breathing index in intensive care unit patients. Intensive Care Med 2008;34(3):505-510.

37. Desai NR, Myers L, Simeone F. Comparison of 3 different methods used to measure the rapid shallow breathing index. J Crit Care 2012; 27(4):418.e1-418.e6.

38. Bien MY, Hseu SS, Yien HW, Kuo BI, Lin YT, Wang JH, Kou YR. Breathing pattern variability: a weaning predictor in postoperative patients recovering from systemic inflammatory response syndrome. Intensive Care Med 2004;30(2):241-247.

39. Wysocki M, Cracco C, Teixeira A, Mercat A, Diehl JL, Lefort Y, et al. Reduced breathing variability as a predictor of unsuccessful patient separation from mechanical ventilation. Crit Care Med 2006; 34(8):2076-2083.

40. Bien MY, Shui Lin Y, Shih CH, Yang YL, Lin HW, Bai KJ, et al. Comparisons of predictive performance of breathing pattern variability measured during T-piece, automatic tube compensation, and pressure support ventilation for weaning intensive care unit patients from mechanical ventilation. Crit Care Med 2011;39(10):2253-2262.

41. Esteban A, Frutos F, Tobin MJ, Alía I, Solsona JF, Valverdú I, et al. A comparison of four methods of weaning patients from mechanical ventilation. Spanish Lung Failure Collaborative Group. N Engl J Med 1995;332(6):345-350.

42. Vitacca M, Vianello A, Colombo D, Clini E, Porta R, Bianchi L, et al. Comparison of two methods for weaning patients with chronic obstructive pulmonary disease requiring mechanical ventilation for more than 15 days. Am J Respir Crit Care Med 2001;164(2):225230.

43. Perren A, Domenighetti G, Mauri S, Genini F, Vizzardi N. Protocoldirected weaning from mechanical ventilation: clinical outcome in patients randomized for a 30-min or 120-min trial with pressure support ventilation. Intensive Care Med 2002;28(8):1058-1063.

44. Su KC, Tsai CC, Chou KT, Lu CC, Liu YY, Chen CS, et al. Spontaneous breathing trial needs to be prolonged in critically ill and older patients requiring mechanical ventilation. J Crit Care 2012; 27(3):324.e1-324.e7.

45. Chien JY, Lin MS, Huang YC, Chien YF, Yu CJ, Yang PC. Changes in B-type natriuretic peptide improve weaning outcome predicted by spontaneous breathing trial. Crit Care Med 2008;36(5):1421-1426.

46. Moore CL, Copel JA. Point-of-care ultrasonography. N Engl J Med 2011;364(8):749-757.

47. Ouanes-Besbes L, Dachraoui F, Ouanes I, Bouneb R, Jalloul F, Dlala $\mathrm{M}$, et al. NT-proBNP levels at spontaneous breathing trial help in the prediction of post-extubation respiratory distress. Intensive Care Med 2012;38(5):788-795.

48. Teixeira C, da Silva NB, Savi A, Vieira SR, Nasi LA, Friedman G, et al. Central venous saturation is a predictor of reintubation in difficult-to-wean patients. Crit Care Med 2010;38(2):491-496.

49. Caille V, Amiel JB, Charron C, Belliard G, Vieillard-Baron A, Vignon P. Echocardiography: a help in the weaning process. Crit Care 2010; 14(3):R120

50. Lamia B, Maizel J, Ochagavia A, Chemla D, Osman D, Richard C, Teboul JL. Echocardiographic diagnosis of pulmonary artery occlusion pressure elevation during weaning from mechanical ventilation. Crit Care Med 2009;37(5):1696-1701.

51. Nagueh SF, Middleton KJ, Kopelen HA, Zoghbi WA, Quiñones MA. Doppler tissue imaging: a noninvasive technique for evaluation of left ventricular relaxation and estimation of filling pressures. J Am Coll Cardiol 1997;30(6):1527-1533.

52. Vignon P, AitHssain A, François B, Preux PM, Pichon N, Clavel M, et al. Echocardiographic assessment of pulmonary artery occlusion pressure in ventilated patients: a transoesophageal study. Crit Care 2008;12(1):R18.

53. Moschietto S, Doyen D, Grech L, Dellamonica J, Hyvernat H, Bernardin G. Transthoracic echocardiography with Doppler tissue imaging predicts weaning failure from mechanical ventilation: evolution of the left ventricle relaxation rate during a spontaneous breathing trial is the key factor in weaning outcome. Crit Care 2012;16(3):R81.

54. Ferrer M, Sellarés J, Valencia M, Carrillo A, González G, Badia JR, et al. Non-invasive ventilation after extubation in hypercapnic patients with chronic respiratory disorders: randomised controlled trial. Lancet 2009;374(9695):1082-1088.

55. Ferrer M, Valencia M, Nicolas JM, Bernadich O, Badia JR, Torres A. Early noninvasive ventilation averts extubation failure in patients at risk: a randomized trial. Am J Respir Crit Care Med 2006;173(2): 164-170. 